\title{
Pascale BARTHÉLÉMY, Africaines et diplômées à l'époque coloniale (1918-1957)
}

Rennes, Presses universitaires de Rennes, 2010) 345 pages

Alice L. Conklin

Traducteur : Anne Hugon

\section{(2) OpenEdition}

\section{Journals}

\section{Édition électronique}

URL : https://journals.openedition.org/clio/10140

DOI : $10.4000 /$ clio. 10140

ISSN : 1777-5299

Éditeur

Belin

Édition imprimée

Date de publication : 1 mai 2011

Pagination : 301-303

ISBN : 978-2-8107-0157-5

ISSN : 1252-7017

\section{Référence électronique}

Alice L. Conklin, «Pascale BarthéLÉmy, Africaines et diplômées à l'époque coloniale (1918-1957) 》, Clio. Femmes, Genre, Histoire [En ligne], 33 | 2011, mis en ligne le 01 mai 2013, consulté le 01 mai 2022. URL : http://journals.openedition.org/clio/10140 ; DOI : https://doi.org/10.4000/clio.10140

Ce document a été généré automatiquement le 1 mai 2022.

Tous droits réservés 


\title{
Pascale BARTHÉLÉMY, Africaines et diplômées à l'époque coloniale (1918-1957)
}

Rennes, Presses universitaires de Rennes, 2010) 345 pages

\author{
Alice L. Conklin
}

Traduction : Anne Hugon

\section{RÉFÉRENCE}

Pascale BARTHÉLÉMY, Africaines et diplômées à l'époque coloniale (1918-1957), Rennes, Presses universitaires de Rennes, 2010) 345 pages

1 L'excellent ouvrage de Pascale Barthélémy constitue un nouveau titre, très bienvenu, dans la floraison d'études dévolues à ce que Gregory Mann a appelé «la relation contrainte particulière » entre la France et l'Afrique. Pascale Barthélémy s'est penchée sur la petite minorité d'Africaines - à peine un millier au total - issues de la fédération d'Afrique Occidentale Française (AOF) et formées par les Français pour devenir sagesfemmes, infirmières-visiteuses (jusqu'en 1938) ou encore institutrices, donc employées de la fonction publique entre 1918 et la décolonisation. Toutes ont obtenu un diplôme de l'une des deux " grandes écoles de filles » : l'École normale de Rufisque, à partir de 1938, ou l'École de médecine de Dakar (section sages-femmes), dès 1918. Entre 1999 et 2002, l'auteure a interviewé 88 de ces «figures de l'entre-deux ", âgées de 60 à 90 ans (p. 18): des femmes qui ont appris à naviguer entre les différents univers que constituaient leur famille, l'État colonial et les différentes populations parmi lesquelles elles ont travaillé en AOF. Chacun de ces mondes était à la fois genré et hiérarchisé mais pas toujours de la même façon. En se fondant sur de fascinants témoignages oraux, sur des recherches approfondies dans les archives et grâce à une analyse sociologique poussée, Pascale Barthélémy éclaire les stratégies scolaires et professionnelles de 
femmes qui ont évolué dans un contexte raciste qu'elles n'avaient pas choisi mais qui les a façonnées.

L'ouvrage est divisé en trois parties : la première retrace la fondation et l'évolution de chacune des deux "grandes écoles"; la seconde se penche sur la vie quotidienne à l'internat, tandis que la troisième est consacrée au mariage et à la carrière de ces femmes. Le fil rouge du récit est constitué par les autorités coloniales plus que par les communautés dont ces diplômées sont issues ou dans lesquelles elles travaillent. Avant la Première Guerre mondiale, seuls les missionnaires installés sur la côte sénégalaise ou au Dahomey s'intéressent à la scolarisation des Africaines. Après le conflit, l'inquiétude des autorités concernant le manque de main-d'œuvre les amène à former les premières sages-femmes modernes. C'est l'avènement du Front populaire et les pressions exercées par des femmes françaises qui expliquent la création d'une École normale de jeunes filles, destinées à promouvoir l'instruction féminine à travers toute l'AOF. Les réformes de l'après Seconde Guerre mondiale offrent de nouvelles opportunités aux hommes et aux femmes (avec l'introduction du baccalauréat) mais sans modifier profondément la formation dispensée dans les deux grandes écoles. De même, la carrière de sage-femme demeure plus populaire que celle d'institutrice sur l'ensemble de la période.

Dès l'origine, le système fédéral de l'AOF pousse au recrutement d'élèves provenant des huit colonies, tandis que les jeunes diplômées sont destinées à servir alternativement dans tous les territoires. Les Français espèrent qu'elles épouseront des Africains diplômés, pour former des unions monogames, des familles nucléaires et des foyers «modernes ». En bref, les stéréotypes raciaux et de genre importés de la métropole constituent le socle de ce projet, lui-même renforcé par les formes africaines de la domination masculine. Les autorités n'ayant jamais dévolu de budget conséquent à l'instruction des filles, celle-ci a moins progressé que celle des garçons : à la veille des indépendances, le taux de scolarisation primaire des filles était de 3,5\%, soit une fille pour trois garçons (p. 281-282).

4 Pascale Barthélémy a méticuleusement retracé le parcours de 164 femmes, soit 16,5\% de l'ensemble des diplômées de la période. Au début, la scolarisation des filles ne soulevait pas l'enthousiasme des familles, privées de cette main-d'œuvre supplétive. Dans les villes côtières où les contacts avec l'Occident étaient anciens, comme au Dahomey, le recrutement des fillettes était relativement facile. Mais dans les colonies de l'intérieur, comme au Soudan ou en Haute-Volta, les administrateurs eurent recours au recrutement forcé, enrôlant notamment de jeunes métisses abandonnées par leur père blanc et placées dans des orphelinats. Les métisses représentaient jusqu'à un cinquième des recrues ; cependant, les jeunes filles dont le père africain travaillait dans la fonction publique étaient aussi souvent scolarisées sous l'influence paternelle.

5 Les élèves devaient se montrer particulièrement tenaces pour poursuivre leur formation, qui exigeait d'elles de longs déplacements entre leur colonie d'origine et Dakar, une adaptation à la vie très réglée de l'internat (deux à quatre ans), sans compter les obstacles liés à la formation elle-même. Celles qui fréquentèrent l'École normale entre 1938 et 1945 furent encadrées par la première directrice, Germaine Le Goff, Bretonne charismatique dont le "féminisme français volontiers maternaliste " (p. 111) a laissé un souvenir indélébile aux étudiantes. Le portrait que fait l'auteure de Germaine Le Goff est un modèle d'interprétation nuancée: sans être partisane du gouvernement de Vichy, elle restait fidèle à la doctrine de l'éducation adaptée, typique 
de l'entre-deux-guerres, et se montrait favorable à ce que «l'on garde ce qu'il y a de bien ici, et que l'on prenne ce qui est mieux ailleurs » (p. 134).

6 Les étudiantes étaient invitées à « demeurer africaines » tout en internalisant l'idée de la supériorité française : ainsi, elles apprenaient le savoir-faire domestique bourgeois, appliqué à la préparation de plats africains «traditionnels». Dans les deux établissements, l'enseignement se faisait bien entendu en français. En dépit de cette «intrusion violente dans leur représentation $d u$ monde", les normaliennes apprenaient à «mobiliser, selon les circonstances, différents registres». A posteriori, elles abordent aujourd'hui « ce processus de façon positive, sans doute parce qu'il leur a procuré une position privilégiée au sein de leurs sociétés respectives» (p. 135).

7 Cependant, même ce privilège relatif avait un prix : selon une citation, «il y tant d'empêchement au bonheur quand on est née femme noire et qu'on a reçu une éducation française» (p. 233). Ces jeunes diplômées quittaient généralement l'école vers l'âge de 21 ans. En dépit de leur position subordonnée dans une administration coloniale qui payait mieux les fonctionnaires français que les Africains, institutrices et sages-femmes gagnaient souvent mieux leur vie que nombre d'hommes africains. Cette situation, combinée au manque d'alternatives, explique que peu d'entre elles aient abandonné leur carrière, même lorsqu'elles étaient en butte aux critiques, aux résistances de celles et ceux qu'elles cherchaient à éduquer, ou encore aux discriminations de genre, avant comme après la décolonisation.

Presque toutes ces femmes ont épousé des "évolués », souvent choisis par leur famille mais avec leur consentement tacite. Sous la pression de leur mari, ces femmes qualifiées ont eu de nombreux enfants. Ensemble, ils ont opté pour un mode de vie européen et décidé de scolariser leurs filles, montrant ainsi leur adhésion à « une forme nouvelle d'épanouissement professionnel et d'engagement " pour les femmes (p. 260). L'auteure conclut que "l'investissement [de ces femmes] dans la préservation d'un mémoriel commun centré sur les années d'école, décrites comme celles de toutes les espérances » (p. 283), en dit long sur les batailles qu'elles ont dû mener par la suite. Aucune d'entre elles n'a vraiment atteint l'autonomie à laquelle elles aspiraient. Et c'est en dépit du colonialisme que "les diplômées sont devenues des actrices d'un changement social», même si le système colonial leur avait ouvert de nouveaux horizons.

9 Cet ouvrage, écrit avec élégance, est un modèle de récit, toujours nuancé et rendant bien compte de la complexité des processus. Les témoignages oraux y révèlent un système oscillant entre contraintes et opportunités, négociées avec plus ou moins de bonheur par des générations successives de femmes dont il nous reste encore beaucoup à apprendre. 